\title{
Addressing the Impact of COVID-19 and Non-Pharmaceutical for Perception Tourism Using Frequentist PLS-SEMs
}

\author{
Pahrudin Pahrudin ${ }^{1,5}$, Li-Wei Liu ${ }^{2}$, Shao-Yu Li ${ }^{3 *}$, Didy Ika Supryadi ${ }^{4}$ \\ ${ }^{1}$ Department of Business Administration, Chaoyang University of Technology, 168, Jifeng E.Rd, Taichung, Taiwan \\ ${ }^{2}$ Department of Leisure and Service Management, Chaoyang University of Technology, 168, Jifeng E.Rd, Wufeng District, \\ Taichung 41349, R.O.C, Taiwan \\ ${ }^{3}$ Language Center of Chaoyang University of Technology, 168, Jifeng E.Rd, Wufeng District, Taichung 41349, R.O.C, Taiwan \\ ${ }^{4}$ Faculty of Economic and Business, University of Mataram, Lombok, West Nusa Tenggara, Indonesia \\ ${ }^{5}$ Faculty of Social Science and Economic, Hamzanwadi University, Lombok, West Nusa Tenggara, Indonesia
}

\begin{abstract}
The pandemic Covid-19 has been changing tourist behavior to visit a tourism destination. This study aims to investigate tourist' visit intention after Covid-19 pandemic period in Indonesia by addressing the Covid-19 phenomenon, health consciousness and theory planned behavior framework. To answer hypotheses in this study, Confirmatory Factor Analysis-Structure Equation Model is used with quantitative approach. The research model is examined by SEM-PLS, using SmartPLS-3 software to analyze research framework. The results show that Covid-19 perception had not significantly impacted attitude, subjective norm, perceived behavioral control and intention. However, the perception of Covid-19 has a significant impact on non-pharmaceutical intervention, which in turn delivers a significant impact on attitude, subjective norm, perceived behavior control and visit intention. The hypothesis presumes that attitude, subjective norm, and perceived behavior control all have significant impact on intention to visit. In contrast, variable of health consciousness works less impact on intention to visit. This study makes significant contribution to the tourism literature by considering health issue and tourist visit behavior after Covid-19 period in Indonesia.
\end{abstract}

\section{Keywords:}

Perception of COVID-19;

TPB; Tourism;

Non-pharmaceutical;

Health Consciousness.

\section{Article History:}

Received: 28 August 2021

Revised: $\quad 02 \quad$ November 2021

Accepted: $\quad 12$ November 2021

Published: $\quad 17 \quad$ November 2021

\section{1- Introduction}

Since the early May of 2020, Covid-19 has put an indenture to the economic wholeness in Indonesia due to the largescale imposition of restriction regulations. Without exception, tourism has been under the sway of the imposition [1, 2]. In this period, the Covid-19 pandemic is making a negative impact to economy, especially in tourism sector with the decrease tourist arrival down to 78\%, resulting in US\$ 1.2 trillion income loss and 120 million un-employments. Tourism sector has been playing important role in global employment and contribution to GDP in some countries [3]. However, Covid-19 has reduced great number of tourists since its outbreak, a result of which has greatly damaged the income of tourism industry and changed the behavior of tourist [4-6].

The pandemic Covid-19 has been delivering great impacts to all of countries over the world and Indonesia is no exception. Based on the data [7], the cases were confirmed around 4.174.216, and around 139,415 confirmed deaths.

*CONTACT: izzy@cyut.edu.tw

DOI: http://dx.doi.org/10.28991/esj-2021-SPER-15

(C) 2021 by the authors. Licensee ESJ, Italy. This is an open access article under the terms and conditions of the Creative Commons Attribution (CC-BY) license (https://creativecommons.org/licenses/by/4.0/). 
According to the Indonesia travel agent association, the tourism sector has seen $90 \%$ drop in sales, with possible loss of US $\$ 245$ due to withdrawals [8]. In airline industry, flights arrival and departures were also down by more than $95 \%$ compared to the previous year or in 2019 [9]. Hotel sector has been impacted by Covid-19 because the availability rate was only $19.7 \%$ in June 2020 compared to $52.3 \%$ in the previous year (2019) in same month [8]. All of the facts indicated that tourism and hospitality industry have received serious impact of Covid-19. Also, the pandemic has affected the local tourist visit intention; tourists would rather stay put than going out to take the risk of being infected by Covid-19.

However, tourists are rarely aware that their decision to cancel their visit would set off a sequence of events involving the government, hotel services, restaurant operations, the tourism business, and others. This study classifies the perceived health caused by Covid-19, which has set up a barrier in the world, keeping tourists from embarking traveling of any kinds. For example, if people planning to go to a specific location believe Covid-19 poses a health risk, such as secondary ailments like fever and cough, they may decide to postpone their trip [10]. In the pandemic era, tourists would reduce health risk in travelling when personal non-pharmaceutical intervention (NPI) is their priority concern.

The individual non-pharmaceutical intervention, which includes pandemic awareness, healthy lifestyle practices, social distance, and pre- and post-trip health checks, has risen to the top of the priority list since it is the most effective approach to avoid transmitting the virus while visiting [11]. In this regard, NPI may create the opportunity for international or domestic tourism to effectively ease up the tourism risk when antivirals and vaccinations are still developed in the lab, painstakingly [12]. In this regard, this research predicts how NPI can give a positive message to tourists' traveling intention in Covid-19 period based on the Theory of Planned Behavior (TPB).

Many experts in tourism, social psychology, and consumer behavior think that perceived risk factors will eventually alter particular intention in decision-making or attractiveness to visit a destination $[6,13,14]$. The aim of this study is addressing the impact of Covid-19 and non-pharmaceutical intervention by applying the Theory of Planned Behavior to visit a destination in post-pandemic period of Indonesia. The Indonesian domestic tourists' intention to travel is also examined since TPB is a useful frame work to predict tourists' intention and behaviors, even their initial decision to visit a destination [15-17]. In addition, this study also will provide comprehensive information on tourists' visit intention and the current study will enhance the theoretical framework in tourism industry, as well as provide an examining of health consciousness during and post pandemic Covid-19.

As said, we also address the variable of perception of Covid-19 in intention to visit a destination in pandemic Covid19 period and non-pharmaceutical intervention. Then, we perform the health consciousness on intention to visit. Therefore, the study contributes to build concept and framework that explain the decision of local tourists to visit a destination in post-pandemic Covid-19 period based on the idea of risk and public health. Two major points are being provided by this paper: one is that an insight is given to local tourists to consider the risk and health factor who want to visit a destination in post Covid-19 in Indonesia; the other is that relevant knowledge of Covid-19 is useful to policy maker or the government when considering the non-pharmaceutical as vital prevention to avoid the spread of risk Covid19 while travelling. The aims of this study are: 1) to address the impact of Covid-19 through the Theory of Planned behavior (TPB) construct toward visit intention; 2) to find out the impact role of public health (non-pharmaceutical intervention and health consciousness) toward visit intention through Theory of Planned Behavior constructs. This empirical analysis can help the stakeholders and the government to make policy about visiting destination in Indonesia during the pandemic Covid-19. However, in the context of Covid-19, academics and researchers have not adequately investigated the adoption of TPB and health sectors such as non-pharmaceutical intervention and health consciousness toward visit intention following pandemic. Filling this research gap will provide insight and contributions about the intention to visit a destination using behavior theory in the Covid-19 pandemic era, and the current study is conducted as part of the contribution to theoretical improvement in tourism sectors related to health post Covid-19 pandemic.

The study's structure is as follows. Section 2 relates literature review and hypotheses development from the concept of risk perception of Covid-19, TPB theory, NPI (non-pharmaceutical intervention) and health consciousness. Section 3 details with methodology, data collection procedures and questionnaire development. Section 4 discusses present data analysis, results, discussion. Section 5 explains the conclusion, recommendation and future direction. References are given in the last section in this study.

\section{2- Literature Review and Hypotheses Development}

The World Health Organization (WHO) declared in 2019 that the pandemic virus H1NI has been elevated to the sixth level due to an increase in the number of affected people worldwide [12]. According to St. Michael's Hospital, epidemics spread quickly by air transportation, such as airplanes, because the airline may convey a big number of people from one location to another at the same time. In the instance of Covid-19, more than fifty airline companies have cancelled flights from and to nations such as China, Italy, Australia, Russia, and the United States since early February 2020, and these governments have also issued travel warnings at the same time [18]. Tourists have what is known as consumer perception, which contains their comprehension of information, method, behavior, and matter. [12].

The consumer's or tourist's view of the disease and its repercussions have forced a new routine in the tourism sector as the epidemic has gotten more serious and governments have had to adjust to quarantine and adapt lockdown measures. 
Some researchers have already shown that tourists' perceived risk while travelling determines their attitude and influences their behavioral intention [19, 20]. Also, risk perception reveals that risk perception works a considerable influence upon the subjective norm and perceived behavioral control [21]. Generally, lower risk levels lead to positive attitudes and increase levels of confidence in themselves, consequent upon which their family or friends will show positive attitudes toward the desired behavior, and increase perceptions of their own ability to perform the desired action [22].

\section{2-1- The Relationship Between Perception of COVID-19, Attitude, Subjective Norm, Perceive Behavioural Control, Non-Pharmaceutical Intervention and Intention to Visit}

NPI is the practices to sharpen tourists' perception of risk of Covid-19 before or after travel to a destination in pandemic era [23]. In 2009, perception of H1N1 had an impact on non-pharmaceutical intervention [14]. Another study also shows that NPI such as wearing a face mask, keeping social distancing and practicing life hygiene are the ways in preventing the spread of disease. Malaysians attempt to prevent symptoms like cough, runny nose, fever, and other illnesses that a high number of packed pilgrims may have by requiring them to wear masks and adjust NPI at Mecca. [24]. It can be concluded that the risk perception of Covid-19 has a direct affect to tourists who plan to visit a local destination using NPI to protect themselves from Covid-19. Based on these considerations, the following hypotheses are developed:

H1: Perception of Covid-19 significantly affects attitude;

H2: Perception of Covid-19 significantly affects subjective norm;

H3: Perception of Covid-19 significantly affects perceived behavioral control;

H4: Perception of Covid-19 significantly affects non-pharmaceutical intervention;

H5: Perception of Covid-19 significantly affects intention to travel.

\section{2-2-The Relationship between Non-pharmaceutical Intervention, Attitude, Subjective Norm, Perceive Behavioral Control and Intention to Visit}

Social distancing, living at home or working from home, self-quarantine, and travel prohibitions are examples of health-protection practices that have had a serious effect on tourism. The tourism business has traditionally been one of the most vulnerable sectors that need special attention, and it is imperative that it becomes more robust to threats such as terrorism, earthquakes, Ebola, SARS, and Zika [19]. The pandemic, on the other hand, has started a full-scale assault on people's lives, since the fundamental aspect of this pandemic is that it has had a massive worldwide impact, resulting in global recessions and depressions [25].

NPI is one of the treatments that use preventative strategies and systems to keep people safe from disease. [26]. Physical or social separation, personal quarantine, continuous health monitoring, and hygiene monitoring are all examples of NPI [27]. Keeping a safe distance during a pandemic can help prevent the virus from spreading. Working from home, shutting public spaces such as schools, markets, stadiums, and theaters, avoiding big gatherings, decreasing access to public transit, and diminishing human interaction are all examples of social distancing. Handwashing with soap, wearing a mask, and protecting one's own face with hands when coughing are all examples of hygiene precautions [28]. Some methods can apply to reduce the influence of the risk pandemic Covid-19 are personal protection, quarantine and contact tracking [29].

Risk perception will affect tourists' intention to travel [30]. Risk perception is closely related to unclarity, worry and fear in tourists [31]. Tourists' thoughts are constantly fully engaged with the notion of peace, security, and stability in any scenario while making the decision to visit a specific area. Global health risks are one element that can have a direct impact on visitors' attitudes and activities. A study [32] points out that Covid-19 is expected to have an influence on Chinese visitors' consumption patterns, given the rising popularity of free and autonomous travel, luxury travel, and well-being tourism. If the estimate is valid, worldwide tourism will be impacted.

However, tourists' perceptions of risk might influence their travel decisions [33]. A study from (Reisinger \& Mavondo, 2005) [10] reports that the risk is "the cognitive possibility of being exposed to risks and hazards." Tourists may choose to alter their trip plans and behavior if they sense the potential risk. As a result, Covid-19 may influence visitors' travel decisions, according to this research. Tourists who choose to travel abroad despite being warned about the possibility of contracting a pandemic should take extra measures [10]. Based on [12], tourists can use some NPI ways to reduce the probability of infection: keeping oneself with updates of pandemic, strengthening personal hygiene during travel, keeping a safe distance from questionable persons and situations, as well as adhering to social distancing conventions. 
Measuring the temperature of people at hotel entrances, wearing mask in public places, having a special health care unit for emergencies, using disposable equipment, informing tourists constantly about the pandemic and using NPI can help continue tourists' intention to visit their desired destinations. In short, tourists will make decision about their trip based on non-pharmaceutical intervention knowledge. The followings are developed hypotheses based on the explanation of relationship among NPI, attitude, subjective norm and perceived behavioral control.

H6: Non-Pharmaceutical Intervention significantly affects attitude;

H7: Non-Pharmaceutical Intervention significantly affects Subjective Norm;

H8: Non-Pharmaceutical Intervention significantly affects perceive behavioral control;

H9: Non-Pharmaceutical intervention significantly affects intention to visit.

\section{2-3-Theory of Planned Behaviour and Intention to Visit}

TPB is a sociopsychology theory that is used to anticipate human intention and behavior. Theory Reasoned Action is the basis of this theory (TRA) by Ajzen (1977) [34]. The fundamental element in TRA is a person's attitude and subjective norm which influence behavior intention and, in turn, actual behavior. As a result, in the TPB theory, Attitude, Subjective Norm, and Perceived Behavioral Control are the major subjects used to explain the behavioral intention [35, 36].

On the one hand, the intention process is separated into two main points: attitude toward behavior and subjective norm, while on the other hand, non-volitional processes view behavior control as the most important aspect [37, 38]. In the TPB paradigm, behavior intention is the major proximate of absolute behavior/action [17, 39]; and in the TPB model, intention is an element of the attitude toward behavior, subjective norm, and perceived behavior control [40]. To put it another way, volitional and non-volitional factors combine to form an individual's purpose [39, 41]. Theory reaction action, on the other hand, is the desire or ready to predict people's behavior [35, 36, 40]. The desire or choice of tourists to visit a location is influenced by their attitude and behavior [40, 42, 43]. It signifies that the attitude expresses a broad personal opinion regarding a certain behavior, either positively or negatively $[35,38]$. Tourists' critical attitudes toward conduct intention are referred to as subjective norms $[41,44]$. This suggests that Subjective Norms are a personal idea used in a social environment to motivate people to behave or not act in certain situations [36, 39].

Furthermore, one of the major variables of behavioral control is the intention of visitors [42]. This is a non-volitional element that relates to a person's assessment of their capacity to behave in a certain activity [38]. Attitude, Subjective Norms, Perceived Behavioral Control, and Intention are all part of the TPB hypothesis, which has been tested and expanded to tourist and consumer behavior research [42, 44, 45]. Research by Ajzen (1991) [37] demonstrates that TPB's theory is experimentally validated, in which a favorable attitude toward the action, perceived social pressure, and perceived capacity to take action all have a beneficial influence on a customer's behavioral intention. Three factors like attitude, subjective norm, and perceive behavioral control of Theory Planned Behavioral (TPB) are expected to have a substantial influence on the assessment of tourists' desire to visit a destination using specific types of literature. The hypotheses are:

H10: Attitude variable has impact on tourists' visit intention post Covid-19 pandemic;

H11: Subjective norm variable has impact on tourists' visit post-Covid-19 pandemic;

H12: Perceive behavioral control variable has impact on tourists' visit intention post-covid pandemic.

\section{2-4- Health Consciousness and Intention to Visit}

Most theories claim that health consciousness is linked to disease prevention motivation or primary conduct to enhance health [46]. Furthermore, health consciousness refers to one's readiness to live a healthy lifestyle [47, 48]. Thus, in terms of healthy behavior and health self-consciousness, health consciousness refers to care about one's health and quality of life $[46,49]$. According to certain research, one's health consciousness is linked to one's interest in healthy foods [50, 51]. As a result, health-conscious consumers would evaluate food quality while purchasing meals [52, 53]. Health consciousness relates to people's awareness of their own health, their concern with health, and their care for their own personal health [54]. During the Covid-19 pandemic, health-conscious travelers are acutely aware of the significance of maintaining good health while traveling; as a result, they will adopt health-promoting attitudes and practices to safeguard their health. To prevent the spread of the Covid-19 virus, health awareness is critical in the tourism sector.

According to several studies, persons with a high level of health consciousness are more likely to choose a better lifestyle $[55,56]$. Other studies have emphasized the importance of health consciousness in health behaviors such as purchasing healthy foods and seeking medical service $[57,58]$. Simply said, travelers with a better degree of health 
awareness are more ready to participate in activities. Tourists with a poor degree of health knowledge, on the other hand, will find it impossible to visit a place during Covid-19 pandemic. As a result, it would be beneficial to investigate if this variable has an influence on the intention to visit a place in and after Covid-19 epidemic. The following hypothesis is offered based on the above literature:

H13: Health consciousness significantly affects intention to travel.

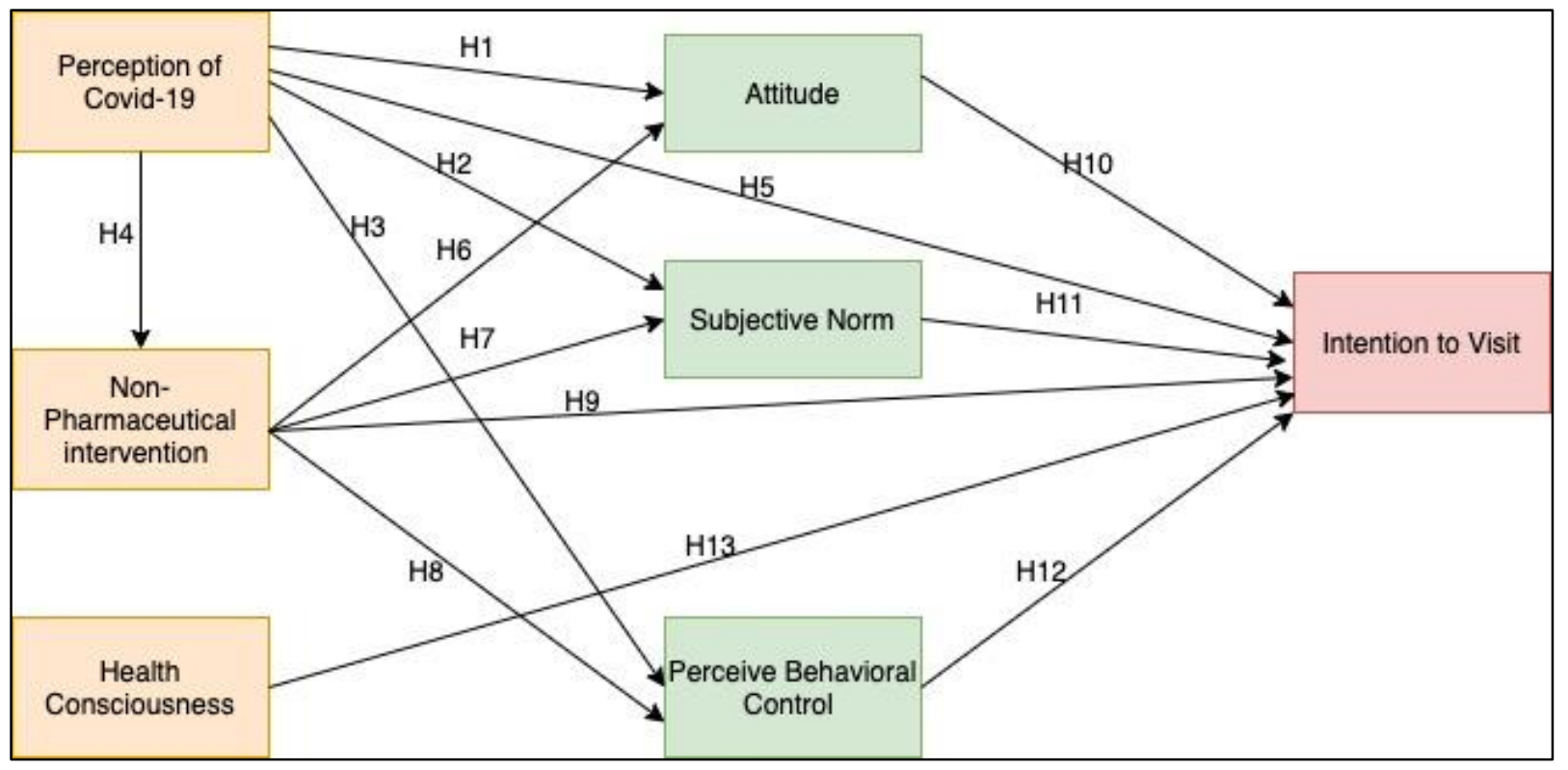

Figure 1. Research Framework.

\section{3- Method}

\section{3-1-Step Construction of Frequentist PLS-SEMs}

In Equation 1 the number of latent variables is represented as $p$, and the latent path number toward latent variables is represented as q. The constant variables in PLS-SEM are represented by $\beta \_j i$ and $\beta \_j 0$. The latent variable is described as $\eta$, and the error of the structural model as $\zeta$. The PLS-SEM approach for the structural model is assumed by [59, 60]. In line with this, the expected value of the equation is obtained as follows:

$\eta_{j}=\beta_{j 0}+\sum_{i \neq j}\left(\beta_{j i} \eta_{i}\right)+\zeta_{j}$

$\mathrm{E}\left(\eta_{j} \mid \forall \eta_{i}\right)=\beta_{j 0}+\sum_{i \neq j}\left(\beta_{j i} \eta_{i}\right)$

In Equations 1 and 2 we assume $\operatorname{cov}\left(\eta_{i}, \xi_{j}\right)=0$, this indicates that exogenous latent variables have no relationship with each other and structural model errors. The measurement formula in the frequentist PLS-SEMs model is described in Equation 3:

$y_{k}=\lambda_{k j o}+\lambda_{k j} \eta_{j}+\varepsilon_{k}$

Manifest variables are assumed to have one latent variable and are grouped into separate blocks. Each manifest variable is assumed to belong to only one latent variable. Because the weight of the latent variable is not known, standardization is needed in order to avoid scale [61-63]. These latent variables are assumed to have the same scale of variance as one. The expected value of the equation is as follows:

$\mathrm{E}\left(\eta_{j} \mid \eta_{j}\right)=\lambda_{k j o}+\lambda_{k j} \eta_{j}$

The expected value in the Equation $4 \operatorname{cov}\left(\varepsilon_{k} \mid \eta_{j}\right)=0$, means the measurement model error is not correlated with the latent variables in the same block. If the equation is substituted into the Equation 5, then we can get the Equation 6 , 7 , and 8 , respectively.

$y_{k}=\lambda_{k j 0}+\lambda_{k j}\left(\beta_{j 0}+\sum_{i \neq j}\left(\beta_{j i} \eta_{i}\right)+\zeta_{j}\right)+\varepsilon_{k}$

$y_{k}=\lambda_{k j 0}^{*}+\lambda_{k j}\left(\sum_{i \neq j}\left(\beta_{j i} \eta_{i}\right)\right)+\varepsilon_{k}^{*}$ 
$\lambda_{k j 0}^{*}=\lambda_{k j 0}+\lambda_{k j} \beta_{j 0}$

$\varepsilon_{k}^{*}=\lambda_{k j} \zeta_{j}+\varepsilon_{k}$

This equation was introduced by Wold (1982) [64] as a substitute for the latent variable or abbreviated as SELV (Substitutive Elimination of the Latent Variable). The description of SELV relates the manifest variables to the endogenous latent variables by means of a structural model within each block of the manifest variables.

$E(\theta)=\left[\begin{array}{ll}\sum_{y y}(\theta) & \sum_{y x}(\theta) \\ \sum_{x y}(\theta) & \sum_{x x}(\theta)\end{array}\right]$

$E(\theta)=\left[\begin{array}{cc}\bigwedge_{y}(1-\mathrm{B})^{-1}\left[\Gamma \Phi \Gamma^{\prime}+\Psi\right](1-\mathrm{B})^{-1^{\prime}} \Lambda_{y}^{\prime}+\Theta_{g} & \bigwedge_{y}(1-\mathrm{B})^{-1} \Gamma \Phi \Lambda_{x}^{\prime} \\ \bigwedge_{y} \Gamma \Phi \Gamma^{\prime}(1-\mathrm{B})^{-1^{\prime}} \Lambda_{y}^{\prime} & \Lambda_{x} \Phi \bigwedge_{x}^{\prime}+\Theta_{\delta}\end{array}\right]$

$E(\theta)=\operatorname{Cov}\left(\begin{array}{l}Y \\ X\end{array}\right)=\left[\begin{array}{ll}\operatorname{Cov}(Y, Y) & \operatorname{Cov}(Y, X) \\ \operatorname{Cov}(X, Y) & \operatorname{Cov}(X, X\end{array}\right]=\left[\begin{array}{cc}\sum_{(\text {pxp }}^{y y}(\theta) & \sum_{(\text {pxq }}(\theta) \\ \sum_{q x y}^{x y}(\theta) & \underset{(q x q)}{\sum_{\text {xx }}(\theta)}\end{array}\right]$

We may consider, $\sum_{y y}(\theta)$ as a covariance matrix y;

$\sum_{y y}(\theta)$

$\sum_{y y}(\theta)=\operatorname{Cov}(Y, Y)=E\left(Y Y^{\prime}\right)$

$\sum_{y y}(\theta)=E\left[\begin{array}{lll}\left(\Lambda_{y} \eta+\varepsilon\right) & \left.\left(\Lambda_{y} \eta+\varepsilon\right)^{\prime}\right]\end{array}\right.$

$\sum_{y y}(\theta)=\Lambda_{y} E\left(\eta \eta^{\prime}\right) \Lambda_{y}^{\prime}+0+0+\Theta_{\delta}$

$E\left(\eta \eta^{\prime}\right)$ can be obtained in advance by changing $\eta$ din reduced form. The reduced form of the simultaneous equation is the form of the endogenous variable expressed as the function of the exogenous variable and the error variable only. The reduction form of $\eta=\mathrm{B} \eta+\Gamma \xi+\zeta$ are as follows:

$\eta=B \eta+\Gamma \xi+\zeta$

$\eta-B \eta=\Gamma \xi+\zeta$

$(1-B) \eta=\Gamma \xi+\zeta$

$(1-B) \eta=\Gamma \xi+\zeta$

$\eta=(1-B)^{-1} \Gamma \xi+(1-B)^{-1} \zeta$

Towards Equation 13 is the reduced form of the equation $\eta=B \eta+\Gamma \xi+\zeta$, thus we get Equation $14 E\left(\eta \eta^{\prime}\right)=$ $E\left[\left((I-B)^{-1} \Gamma \xi+(I-B)^{-1} \zeta\right)\left((I-B)^{-1} \Gamma \xi+(I-B)^{-1} \zeta\right)^{\prime}\right]$

$=(I-B)^{-1} \Gamma E\left(\xi \xi^{\prime}\right) \Gamma^{\prime}(I-B)^{-1^{\prime}}+(I-B)^{-1} E\left(\zeta \zeta^{\prime}\right)(I-B)^{-1^{\prime}}$

$=(I-B)^{-1} \Gamma \Phi \Gamma\left(\xi \xi^{\prime}\right)(I-B)^{-1 \prime}+(I-B)^{-1} \Gamma^{\prime} \Psi(I-B)^{-1 \prime}$

$=(I-B)^{-1}\left[\Gamma \Phi \Gamma^{\prime}+\Psi\right](I-B)^{-1^{\prime}}$

\section{3-2-Data Collection Procedure and Questionnaire Development}

The participants in this study are Indonesian visitors who desire to visit a local destination in the post Covid-19 outbreak in Indonesia. The data for this study are collected using an online survey. An online survey is employed in the travel and hospitality industry since it is more efficient [65-67], particularly when the global pandemic COVID-19. In this case, an online survey is a far more effective way of gathering information. The data are gathered between November 2020 and February 2021. An online survey questionnaire is provided to potential visitors selected at random via social media, and the questionnaire is shared publicly with people who are interested in visiting a local tourism destination.

Local tourists who will visit a local location in the post-pandemic Covid-19 era in Indonesia are the respondents in this study. A total of 308 people took part in the survey. Some questions were adapted from various sources in order to make this study practicable. TPB constructions adopt the factors from this study. In this study, purposive sampling is utilized to look at who wants to visit a local destination in Indonesia. The Covid-19 perception is adapted from [12], non-pharmaceutical intervention variable developed from [68], Attitude variable adapted from [69, 70], Subjective Norm variable developed from [69, 71], Perceive behavioral control variable adapted from [69-71], visit intention 
variable adapted from [69, 71], health consciousness/health variable risk developed from [73]. Because the respondents in this study are Indonesian tourists, the questionnaire is written in both English and Indonesian. In this study, the scales from prior studies are used, with a Likert-type scale and seven scales (Scale 1: Strongly Disagree, and Scale 7: Strongly Agree).

\section{3-3-Data Analysis}

SPSS and Smart PLS software are used in this study to analyze the data and test the hypotheses, as well as to assess the validity and reliability of the questionnaires. Gender, education, background, age, and other descriptive statuses of respondents are covered. PLS-SEM is used to seek for latent patterns in data and to learn more about the relationships between variables [74]. Confirmatory Factor Analysis is applied to test the validity and reliability construct [75], and to assess the measuring scale that has been constructed using the three criteria. First, latent variable composite reliability (CR) should not be less than 0.7 [76]. Then, to assess the value of convergence validity, average variance extracted (AVE) is employed with the value should 0.5 [77]. Finally, confirmatory factor analysis is used to measure factor loading with the value equally $0.7[76,78]$.

\section{4- Result and Discussion}

\section{4-1-Respondent Characteristics}

The general information of the respondents in this study is explained by their characteristics. The data reveal that male and female respondents are 40 percent and 60 percent, respectively, with 56 percent of the respondents being between the ages of 18 and 24. Senior high school is the most common educational background among respondents, representing approximately 40 percent. The monthly income of the respondents is less than IDR 1.000 .000 , or 54\%. Being student is the occupation of 54 percent of the respondents. The characteristic of respondents is explained in Table 1.

Table 1. Demographic respondent profile $(n=308)$

\begin{tabular}{|c|c|c|c|}
\hline Variable & Responses & Frequency & Per cent \\
\hline \multirow{2}{*}{ Gender } & Male & 124 & 40.3 \\
\hline & Female & 184 & 59.7 \\
\hline \multirow{5}{*}{ Age (year) } & $18-24$ & 172 & 55.8 \\
\hline & $25-34$ & 102 & 33.1 \\
\hline & $35-44$ & 22 & 7.1 \\
\hline & $45-54$ & 10 & 3.2 \\
\hline & More than 55 & 2 & 6 \\
\hline \multirow{4}{*}{ Education } & Senior High School & 122 & 39.6 \\
\hline & Bachelor & 111 & 36.0 \\
\hline & Master & 66 & 21.4 \\
\hline & Doctor & 9 & 2.9 \\
\hline \multirow{5}{*}{ Income Monthly (IDR) } & Less than IDR 1.000 .000 & 167 & 54.2 \\
\hline & IDR 1.000.000-5.000.000 & 102 & 33.1 \\
\hline & IDR 5.000.000-10.000.000 & 28 & 9.1 \\
\hline & IDR10.000.000-15.000.000 & 5 & 1.6 \\
\hline & more than IDR 15.000 .000 & 6 & 1.9 \\
\hline \multirow{6}{*}{ Occupation } & Student & 167 & 54.2 \\
\hline & Full-time job & 56 & 18.2 \\
\hline & Part-time job & 31 & 10.1 \\
\hline & Businessman & 13 & 4.2 \\
\hline & Household keeping & 10 & 3.2 \\
\hline & Professional & 31 & 10.1 \\
\hline
\end{tabular}

\section{4-2- Validity and Reliability}

To assess the value of validity and reliability in this study, composite reliability is employed. There are three indicators to assess the reliability of each item. The value of factor loading based on the suggestion should be more than .50 [79]. Value of composite reliability (CR) should be reach more than 0.70 [80], and the value of Cronbach's alpha, it suggests more than $0.70[76,77]$ and the Average Variance Extracted (AVE) value should be more than 0.50 [77]. The AVE of each potential variable must be larger than 0.50 to be considered the convergent validity, and the test standard of the square root of AVE must be greater than 0.70 to be considered discriminant validity. The Composite 
Reliability of this study has a threshold of value of 0.70 , and all constructs are greater than .70 , indicating that the items in this study are internally reliable. Table 2 summarizes these data. We look at both convergent and discriminant validity to confirm that latent variables are valid. The first, convergent validity, is determined by looking at the average value extracted (AVE) score as well as the loading Factors of each indicator associated to construct. To determine the factor loading, confirmatory factor analysis is used. The AVE value varied from 0.614 to 0.912 is much better than normal values of 0.50 . The factor loading ranges from 0.701 to 0.972 , indicating that all variables are compatible with convergent validity.

The AVE root of the individual potential variable is used in this study to examine the discriminating validity, which should be greater than the common variate correlations of other potential variables and models, as proposed by Chin (1998) [81]. Furthermore, experts recommend that the AVE root test standard be at least equal to or greater than 0.70. Experts also propose that the AVE root test standard be at least equal to, and preferably more than 0.70 [82]. In this research, the root of AVE value is at least 0.70. The square root of the AVE for each concept is compared to the inter construct correlation to determine discriminant validity. The discriminant validity is satisfied when all of the diagonal elements, which are the square root AVE, surpass the inter construct correlations. Table 3 describes discriminant validity.

Table 2. The Construct and item measurement of Factor Loading, AVE, CR and CA.

\begin{tabular}{|c|c|c|c|c|c|}
\hline Construct and Item Measurement & $\begin{array}{c}\text { Factor } \\
\text { Loading }\end{array}$ & AVE & $\mathbf{C R}$ & $\begin{array}{l}\text { Cronbach } \\
\text { Alpha }\end{array}$ & \\
\hline \multicolumn{6}{|l|}{ Perception of Covid-19 } \\
\hline 1. Traveling is risky due to Covid- 19 . & 0.708 & & & & \\
\hline 2. Covid-19 is a frightening sickness. & 0.871 & & & & \\
\hline $\begin{array}{l}\text { 3. Covid-19 is a more hazardous pandemic than SARS or avian } \\
\text { influenza. }\end{array}$ & 0.798 & 0.611 & 0.886 & 0.840 & $\begin{array}{l}\text { Eliminate Question: I have a lot } \\
\text { of knowledge on Covid-19. }\end{array}$ \\
\hline 4. I'm terrified about the Covid-19 sickness. & 0.814 & & & & \\
\hline $\begin{array}{l}\text { 5. People in my immediate vicinity appear to be avoiding travel owing } \\
\text { to Covid-19. }\end{array}$ & 0.705 & & & & \\
\hline
\end{tabular}

\section{Non-Pharmaceutical intervention}

1. Before traveling to another destination, I shall examine the information regarding Covid-19 on the government's website.

2. Before traveling to another location, I will create a first aid pack for Covid-19.

3. When traveling, I shall wash my hands regularly.

4. While traveling, I shall refrain from touching my eyes, nose, or mouth.

5. I'll maintain my distance while traveling.

6. I'll be wearing a mask a lot when traveling.

7. After I return from my trip, I shall control myself and avoid meeting new people for a time.
0.849

0.826
0.778

0.820

\section{1}

0.781

$0.625 \quad 0.921 \quad 0.899$

Remove the inquiry:

Before traveling, I will study and confirm the Covid-19 precautions with the hospital physicians or Covid-19 health centre.

\section{Attitude}

1. When the Covid-19 epidemic is finished, I plan to visit to a local destination that I have previously selected.

2. When the Covid-19 epidemic is over, my friends and I want to trave to a local place that they had initially planned to visit.

$0.901 \quad 0.721 \quad 0.885 \quad 0.806$

3. When the Covid-19 epidemic is finished, most of my close friends advise that I visit a nearby attraction.

\section{Subjective Norm}

1. When the Covid-19 pandemic is finished, I plan to visit to a local destination that I have already picked.

2. When the Covid-19 pandemic is over, my friends and I intend to travel to a local place that they had initially planned to visit.

3. When the Covid-19 pandemic is finished, most of my close friends advise me to visit a nearby attraction.

0.866

Perceive Behavioural Control
1. When the pandemic Covid-19 is finished, I will have time and
possibilities to visit a nearby place that I had planned to visit
previously.


3. Once the Covid-19 epidemic is finished, I am optimistic that I will be

0.887

able to visit a nearby place that I had planned to visit.

0.839

to a local place that I have already picked.

\begin{tabular}{|c|c|c|c|c|c|}
\hline \multicolumn{2}{|l|}{ Visit Intention } & \multirow{4}{*}{0.898} & \multirow{4}{*}{0.963} & \multirow{4}{*}{0.943} & \\
\hline $\begin{array}{l}\text { 1. After the Covid- } 19 \text { pandemic is ended, in the future, I plan to visit a } \\
\text { local destination. }\end{array}$ & 0.938 & & & & \\
\hline $\begin{array}{l}\text { 2. Once this epidemic of Covid-19 has passed, in the future I am } \\
\text { looking forward to seeing a local attraction }\end{array}$ & 0.937 & & & & \\
\hline $\begin{array}{l}\text { 3. After this pandemic Covid-19 has passed, I intend to travel to a } \\
\text { nearby place. }\end{array}$ & 0.967 & & & & \\
\hline & & & & & Remove the Inquiries: \\
\hline Health consciousness/ Risk perceive (health Risk) & & & & & I do not believe that traveling \\
\hline 1. Nowadays, my health is more essential to me than vacation & 0.856 & 0.773 & 0.872 & 0.709 & $\begin{array}{l}\text { will hurt me during pandemic } \\
\text { COVID-19, and I believe that }\end{array}$ \\
\hline 2. My health is very important to me & 0.902 & & & & $\begin{array}{l}\text { traveling will be safe for me if I } \\
\text { follow the health regimen. }\end{array}$ \\
\hline
\end{tabular}

Table 3. Discriminant validity.

\begin{tabular}{|c|c|c|c|c|c|c|c|c|c|c|}
\hline & AVE & $\mathbf{C R}$ & $\mathbf{C A}$ & 1. & 2. & 3. & 4. & 5. & 6. & 7. \\
\hline 1.Attitude & 0.721 & 0.885 & 0.806 & 0.849 & & & & & & \\
\hline 2.Health Consciousness & 0.773 & 0.872 & 0.709 & 0.070 & 0.879 & & & & & \\
\hline 3.Intention to Visit & 0.898 & 0.963 & 0.943 & 0.577 & 0.190 & 0.947 & & & & \\
\hline 4.Non-Pharmaceutical Intervention & 0.625 & 0.921 & 0.899 & 0.178 & 0.470 & 0.435 & 0.790 & & & \\
\hline 5.Perceive Behavioural Control & 0.689 & 0.898 & 0.850 & 0.583 & 0.169 & 0.772 & 0.356 & 0.830 & & \\
\hline 6.Perception of Covid-19 & 0.611 & 0.886 & 0.840 & 0.062 & 0.463 & 0.264 & 0.563 & 0.204 & 0.782 & \\
\hline 7.Subjective Norm & 0.768 & 0.909 & 0.849 & 0.659 & 0.110 & 0.681 & 0.338 & 0.709 & 0.161 & 0.876 \\
\hline
\end{tabular}

Note: AVE: Average Variance Extracted $\mathrm{CR}=$ Composite Reliability, $\mathrm{CA}=$ Cronbach Alpha. The average variance was extracted from the square average variance extracted.

\section{4-3- Capability Index}

The $\mathrm{R}$ values, which are the percentage of the variance of the outer variables that further explain the inner variables, demonstrate the research model's prediction power. In terms of causal relationship analysis (of developed model), it is dependent on whether the standardized route coefficient approaches statistical significance, as well as the explanatory ability of the R square determination model $[77,83]$. Table 4 shows the capability of each variable to explain the research model.

Table 4. Explanatory Capability.

\begin{tabular}{cc}
\hline Variable & R Square \\
\hline Attitude & 0.034 \\
Intention to Visit & 0.665 \\
NPI & 0.317 \\
Perceive Behavioural Control & 0.127 \\
Subjective Norm & 0.115 \\
\hline
\end{tabular}

Table 4 shows the research model from outer variable that further explains the estimated inner model. As shown in table 5, as a consequence of the findings, we can assume that the $\mathrm{R}$ square variable of intention to visit has a value of 0.665 or $66.5 \%$, which explains the model. Variable Non-Pharmaceuticals Intervention is 0.317 or $31.7 \%$, which also explains the model. Variable attitude explains the model by 0.034 or $3,4 \%$, variable subjective explains the model by 0.115 or $11.5 \%$ and variable perceive behavioral control explains the model by 0.127 or $12.7 \%$ in this study. Table 5 shows the proposed model that explains the goodness of fit (SRMR $=0.06$, NFI $\left.0.80, X^{2}=1158.245\right)$.

Table 5. Goodness of Fit.

\begin{tabular}{cccc}
\hline Indicators & $\boldsymbol{X}^{2}$ & NFI & SRMR \\
\hline Cut-off for Good Fit & Close to 0 & $\geq 0.80$ & $\leq 0.08$ \\
Criteria Model & 1158.245 & 0.80 & 0.06 \\
\hline
\end{tabular}




\section{4-4- Hypothesis Testing}

The hypothesis is rejected since the findings demonstrates that perception of Covid-19 has no significant influence on attitude $(\mathrm{H} 1:=-0.056, \mathrm{t}=0.788)$. In the same way, the perception of Covid-19 has no effect on subjective norm $(\mathrm{H} 2$ : $=-0.042, \mathrm{t}=0.612)$. As a result, this theory is rejected. Similarly, variable perception of Covid-19 has no effect on perceived behavioral control $(\mathrm{H} 3:=0.005, \mathrm{t}=0.064)$ and is rejected. The variable impression of Covid-19, on the other hand, has a significant impact on variable non-pharmaceutical intervention $(\mathrm{H} 4:=0.563, \mathrm{t}=11.865)$ or is accepted. The variable non-pharmaceutical intervention has a substantial influence on perceived behavioral control or is accepted (H8: $=0.353, \mathrm{t}=4.553)$, and the variable non-pharmaceutical intervention has a significant impact on intention to travel or is accepted $(\mathrm{H} 9:=0.154, \mathrm{t}=2.547)$. The variable attitude has a substantial influence on the likelihood of visiting or being accepted $(\mathrm{H} 10:=0.138, \mathrm{t}=2.252)$. Subjective norm has a substantial influence on travel intention or is accepted $(\mathrm{H} 11:=0.173, \mathrm{t}=2.299)$, and perceive behavioral control is also accepted or has a big impact on travel intention (H12: $=0.508, \mathrm{t}=7.648$ ). The result of hypotheses testing is shown in the Table 6 .

Table 6. Hypotheses Results.

\begin{tabular}{cccccc}
\hline Hypothesis & Original Sample (Estimated $\boldsymbol{\beta}$ ) & Standard Deviation (STDEV) & T Statistics & P Values & Decision \\
\hline $\begin{array}{c}\text { H1 POC-19 -> } \\
\text { Attitude }\end{array}$ & -0.056 & 0.071 & 0.788 & $0.431^{*}$ & Rejected \\
H2 POC-19 -> SN & -0.042 & 0.069 & 0.612 & $0.541^{*}$ & Rejected \\
H3 POC-19 -> PBC & 0.005 & 0.075 & 0.064 & $0.949^{*}$ & Rejected \\
H4 POC-19 -> NPI & 0.563 & 0.047 & 11.865 & $0.000^{* * *}$ & Accepted \\
H5 POC-19 -> ITV & 0.046 & 0.045 & 1.018 & $0.309^{*}$ & Rejected \\
H6 NPI -> Attitude & 0.209 & 0.073 & 2.880 & $0.004^{* * *}$ & Accepted \\
H7 NPI -> SN & 0.362 & 0.066 & 5.497 & $0.000^{* * *}$ & Accepted \\
H8 NPI -> PBC & 0.353 & 0.078 & 4.553 & $0.000^{* * *}$ & Accepted \\
H9 NPI -> ITV & 0.154 & 0.060 & 2.547 & $0.011^{* * *}$ & Accepted \\
H10 Attitude -> ITV & 0.138 & 0.061 & 2.252 & $0.025^{* * *}$ & Accepted \\
H11 SN -> ITV & 0.173 & 0.075 & 2.299 & $0.022^{* * *}$ & Accepted \\
H12 PBC -> ITV & 0.508 & 0.066 & 7.648 & $0.000^{* * *}$ & Accepted \\
H13 HC -> ITV & -0.018 & 0.034 & 0.541 & $0.589^{*}$ & Rejected \\
\hline
\end{tabular}

***Significant at the $p<0.05$ level (two-tailed). Note: NPI (Non-Pharmaceutical Intervention), HC (Health Consciousness), AT (Attitude), SN (Subjective Norm), PBC (Perceive Behavioral Control), ITV (Intention to Visit).

\section{4-5- Direct and Indirect Effect}

In this study, mediation analysis is used to analyze the role of the mediating variable. According to the findings of this study, the variable NPI has the greatest influence on travel intention (0.563). The variable of perceived behavioral control has a substantial influence on travel intention $(\beta=0.508, \mathrm{t}=7.648)$ and has a favorable impact on travel intention. In light of non-pharmaceutical intervention and perceived behavioral control, perception of Covid-19 has a substantial and beneficial influence on intention to travel ( $\left.\beta_{\text {Perception of COVID-19 }>\text { NPI }>\text { PBC }>\text { ITV }}=0.101, t=3.394\right)$. However, perception of Covid-19 has no significant impact on intention to travel in the context of non-pharmaceutical intervention and attitude $(\beta$ Perception of COVID-19 $>$ NPI-> ATT $>$ ITV $=0.016, t=1.597)$, and variable perception of Covid-19 has no significant impact on intention to travel in the context of non-pharmaceutical and subjective norm ( $\beta_{\text {Perception of COVID-19 }>>\text { NPI-> SN }->\text { ITV }}$ $=0.016, \mathrm{t}=1.918)$. As a result, through non-pharmaceutical intervention, perception of Covid-19 has a considerable influence on attitude. The variable non-pharmaceutical is a significant predictor of Covid-19 perception to subjective norm. Through non-pharmaceutical intervention, the perception of Covid-19 has a considerable influence on perceived behavioral control. In addition, the impression of Covid-19 has a substantial influence on non-pharmaceutical intervention's desire to travel. Another outcome of Covid-19 perception is that it has no significant influence on intention to travel via attitude, perception of Covid-19 on intention to visit through subjective norm, and perception of Covid-19 on intention to visit through perceived behavioral control. Non-pharmaceutical intervention has no significant influence on intention to travel through attitude, subjective norm, or perceived behavioral control, and finally, non-pharmaceutical intervention has no significant impact on intention to travel through attitude, subjective norm, or perceived behavioral control. Table 7 summarizes the findings of all direct and indirect analyses. 
Table 7. The Direct, Indirect and Total Effect of the Structural Model.

\begin{tabular}{|c|c|c|c|c|c|c|}
\hline Independent variable & NPI & HC & ATT & SN & PBC & ITV \\
\hline \multicolumn{7}{|l|}{ Perception of Covid-19 } \\
\hline Direct effect & 0.563 & - & -0.056 & -0.042 & 0.005 & 0.046 \\
\hline \multicolumn{7}{|l|}{ Indirect effect } \\
\hline Perception of Covid-19 -> NPI -> PBC -> ITV & & & & & & $0.101 * * *$ \\
\hline Perception of Covid-19 -> NPI -> ATT -> ITV & & & & & & $0.016^{*}$ \\
\hline Perception of Covid-19 -> NPI -> SN -> ITV & & & & & & $0.035^{*}$ \\
\hline Perception of Covid-19 -> NPI -> Attitude & & & 0.018 & & & \\
\hline Perception of Covid-19 -> NPI -> SN & & & 0.204 & & & \\
\hline Perception of Covid-19 -> NPI -> PBC & & & 0.199 & & & \\
\hline Perception of Covid-19 -> NPI -> ITV & & & & & & $0.087^{* * *}$ \\
\hline Perception of Covid-19 -> ATT-> ITV & & & & & & $-0.008 *$ \\
\hline Perception of Covid-19 -> SN -> ITV & & & & & & $-0.007 *$ \\
\hline Perception of Covid-19 -> PBC -> ITV & & & & & & $0.002 *$ \\
\hline Total effect & 0.563 & & 0.365 & -0.042 & 0.005 & 0.272 \\
\hline \multicolumn{7}{|l|}{ NPI } \\
\hline Direct effect & & & 0.209 & 0.362 & 0.353 & 0.154 \\
\hline \multicolumn{7}{|l|}{ Indirect effect } \\
\hline NPI -> ATT-> ITV & & & & & & $0.029^{*}$ \\
\hline NPI -> SN -> ITV & & & & & & $0.062 *$ \\
\hline NPI $->$ PBC $->$ ITV & & & & & & $0.180^{*}$ \\
\hline Total effect & & & 0.209 & 0.363 & 0.353 & 0.425 \\
\hline \multicolumn{7}{|l|}{ Health Consciousness } \\
\hline Direct effect & & & & & & -0.018 \\
\hline \multicolumn{7}{|l|}{ Indirect effect } \\
\hline Total effect & & & & & & -0.018 \\
\hline \multicolumn{7}{|l|}{ Attitude } \\
\hline Direct effect & & & & & & 0.138 \\
\hline \multicolumn{7}{|l|}{ Indirect effect } \\
\hline Total effect & & & & & & 0.138 \\
\hline \multicolumn{7}{|l|}{ Subjective Norm } \\
\hline Direct effect & & & & & & 0.173 \\
\hline \multicolumn{7}{|l|}{ Indirect effect } \\
\hline Total effect & & & & & & 0.173 \\
\hline \multicolumn{7}{|l|}{ Perceive Behavioural Control } \\
\hline Direct effect & & & & & & 0.508 \\
\hline \multicolumn{7}{|l|}{ Indirect effect } \\
\hline Total effect & & & & & & 0.508 \\
\hline
\end{tabular}

\section{4-6-Discussion}

The hypothesis is accepted based on the findings of this study, which shows that the changing perception of Covid19 has a major influence on non-pharmaceutical intervention in pandemic Covid-19. The Covid-19 and nonpharmaceutical interventions will be considered by tourists, indicating that they are concerned about their health. Consumers believe that non-pharmaceutical intervention is the way to reduce the risk of contagion when visiting or traveling in this study, which is similar to or in line with another field in which consumers believe that nonpharmaceutical intervention is the way to reduce the risk of contagion when visiting or traveling during pandemic [12]. According to the findings, purpose, perceived behavioral control, prior behavior, and non-pharmaceutical intervention are all important variables in tourists' decision-making. As a result, it is crucial to consider the influence of Covid-19 perception and non-pharmaceutical intervention on a person's desire to visit a certain location. 
The findings indicate that Covid-19 perception has no significant influence on the desire to visit a place, indicating that the hypothesis is rejected. This research suggests that the pandemic Covid-19 has no effect on a person's desire to visit a certain location. The perception of danger, on the other hand, is the most important element in determining tourist visit intentions [31]. As a consequence, visitors do not perceive that the Covid-19 pandemic poses a travel danger, and their perception of risk is reduced as a result of government or medical management of the pandemic. Despite the pandemic Covid-19, Indonesian visitors are impacted by the perceptions of others around them, which may have enhanced their desire to visit a destination. The Indonesian government has also been promoting, asking travelers, both foreign and domestic, to follow health procedures such as wearing a mask, maintaining physical distance, and using hand sanitizer when visiting the country.

Based on the findings, the decision of tourists to visit a local location in the pandemic Covid-19 era (in the post pandemic Covid-19 time) is typically important, based on planned behavior theory. In the post-pandemic Covid-19 period, variable attitude has a positive link and importance to variable intention to visit a location. Furthermore, in this study, the variable subjective norm has a positive and substantial effect on the variable intention to visit a location, and the hypothesis is accepted. Perceived behavioral control is the last variable in TPB, and it has a strong influence on and a positive association with the variable desire to visit a nearby place. In the tourist area, the notion of planned behavioral frameworks (attitude, subjective norm, and perceived behavioral control) has been employed and has a favorable link [42, 44, 45]. Perceived behavioral control (PBC) has been found to be a powerful predictor of intention in TPB investigations in previous research [84-87]. Based on the study from [37], the idea of TPB, in which consumers' behavioral intention is positively influenced by their attitude toward action, perceived social pressure, and perceived capacity to act, has a beneficial impact.

In the case of Indonesian tourists, their perceptions of Covid-19 as a risk are unaffected. This research explains why the number of Covid-19 infected people in Indonesia grew dramatically between 2020 and 2021 [7]. In other words, in the setting of Covid-19, Indonesian visitors do not modify their attitude, subjective norm, or perceived behavioral control. The findings of this study suggest that the value of non-pharmaceutical intervention during and after post Covid-19 might influence tourist behavior to visit a destination. It implies that visitors can visit a local destination after a pandemic Covid-19 by following health measures to protect themselves from Covid-19. However, other researchers claim that tourists' attitudes and behavioral intentions are influenced by how they perceive danger when traveling [88, 89]. Perception of risk also contributes to the study's discovery that risk perception has a major impact on subjective norm and perceived behavioral control [21]. Lower levels of risk, in general, result in positive attitudes, improved selfconfidence that their family or friends would display favorable attitudes toward the desired conduct, and increased judgments of their own capacity to undertake the desired action [22].

Non-pharmaceutical intervention (NPI) has a considerable influence on attitude, subjective norm, and perceived behavioral control, as well as whether or not hypotheses are accepted. It is possible to conclude that non-pharmaceutical intervention influences visitors' usage of NPI while traveling. The Indonesian government has promoted nonpharmaceutical interventions to protect society against pandemic Covid-19, such as wearing a mask, maintaining physical distance, being healthy, and washing their hands with soap. Previous research has shown a strong relationship between the variable illness, attitude, and intention $[10,90]$. It can be stated that NPI plays the most important role in preventing the spread of illness, as the study finds a significant relationship between perception of Covid-19, NPI, and intention to visit. This is consistent with [12], who stated that pandemic H1N1 2009 significantly influenced intention to international visit toward non-pharmaceutical intervention. As a consequence, this finding is corroborated by [12] who state that non-pharmaceutical intervention is the primary function for personal preventive in order to lower infection risk and highlight purpose. During a pandemic, health consciousness plays a critical role because it allows people to avoid the spread of sickness or the spread of the virus. Based on the statistical results, the variable health consciousness toward variable intention to visit has no significant influence in this study, and the hypothesis is rejected. This finding reveals that tourists are concerned about their planning to visit in the aftermath of the Covid-19 pandemic and they are not following health precautions while on the trip. As the result, travelers are less concerned about their health while deciding to travel following the pandemic Covid-19. Tourists, according to risk theory, tend to avoid unfavorable encounters and always attempt to enhance their enjoyment. The danger of Covid-19 illness would have an influence on tourists if they are less health concerned. This study's findings are consistent with marketing theory, which states that elevated risk perception influences purchasing behavior [91].

Some researchers' studies show that the tourists' visit intention can give impact by perceiving risk [10, 92, 93]. In marketing field research, the risk is discovered by [94], who believes that consumer behavior involves both risk and uncertainty as a result of their will and discomfort. However, the factors like income, health risk perception, and consumption can give impact to the tourist behavior in pandemic period [95]. All of the criteria mentioned are crucial in inspiring tourists to visit a destination. Furthermore, the Covid-19 disaster contributes significantly to the danger in terms of health risk, as well as the effect of the perception of pandemic risk and tourist confidence. Our findings in this study provide a point of view on disaster risk, including pandemic disaster risk and crisis management perception. As a result, based on the greater impact of COVID-19, our study illustrates how the pandemic affects the tourism industry and leisure. 
Findings of this study indicate that tourists and locals would view Covid-19 as a risk when traveling in post-pandemic Covid-19 areas. The personal NPI for Covid-19 as an adaptable among tourists to visit a location infers six key implications based on the findings of this study, which include the government, agencies, traveler marketers, hospitality sectors, and stakeholders. First, tourist intentions to visit the destination are resilient during the pandemic Covid-19 because the potential of tourists perceives NPI such as hand washing, wearing a mask while traveling, maintaining social distance, and checking the information about the Covid-19 as ways to avoid the spread of illness during a journey. Tourists will be able to be aware of their health consciousness if there is a guideline for NPI hygiene information at public destinations and safety information such as airplane onboard publications and internet information. Second, tourism operators and the government should update all Covid-19 information, conduct NPI campaigns, and raise health awareness during the epidemic. These are the complexities of the situation in the tourism sector while dealing with the pandemic Covid-19, worldwide air transport, and practical concerns in tourism connected to NPI and health consciousness, all of which influence travelers' trip intentions.

\section{5- Conclusion, Recommendation, and Future Direction}

During pandemic Covid-19, the tourism sector has been severely damaged by the pandemic, which results in a shift in visitor behavior. Based on TPB constructs, this study investigates the impact of Covid-19, non-pharmaceutical intervention, and health consciousness on intention to visit a local location in Indonesia during the pandemic Covid-19 era. TPB construct attitude has a substantial influence on intention to visit, subjective norm has a big impact on intention to visit, and the variable perceive behavioral control has a significant impact on intention to travel, according to a deeper analysis. The fluctuating health consciousness, on the other hand, has no effect on the desire to travel. It is critical for all practitioners, tourist marketers, leisure industries, government, and stakeholders who have the time to study this article to understand Covid-19 perception, non-pharmaceutical intervention, health consciousness, and behavior to travel in the pandemic Covid-19 era.

The perception of Covid-19 as a danger, as well as the health sector (non-pharmaceutical intervention and health consciousness) as variables that might impact local tourist behavior to visit a local destination in Indonesia, are examined in this study. This research will equip people's planning to visit a local location in Indonesia during the pandemic of Covid-19 with the knowledge that health is one of the most important factors to consider while avoiding risks like Covid19. The researchers feel that this study can contribute to the tourist sector by assisting the government in making policies for disaster travel, such as during the Covid-19 era.

\section{5-1- Limitation and Future Research}

Our research has limits, but it does provide an opportunity to learn more and do more research. The study looks at how Covid-19, non-pharmaceutical interventions, health consciousness, and TPB conceptions are perceived in the tourism industry, particularly in destination areas. The study investigates the TPB concept in relation to the pandemic Covid-19, and how it relates to tourists' perceptions of Covid-19, non-pharmaceutical interventions, and health awareness when visiting a local destination in Indonesia. First, our research focuses on visitors' intentions to visit a local attraction in Indonesia. However, a new study involving international tourists from various nations might be undertaken. Second, the data are collected using online survey and quantitative approach. Therefore, the next research can apply different approach such as mixed methods or qualitative method to know more about the intention to visit a destination by visitors. The basic concept in this study relates to extend the theory of TPB (theory of planned behavior) and health perspective and risk by measuring the risk of Covid-19. Future research may capture the extension more precisely about the tourist visit intention by considering CHSE (Clean, Health, Sustainability and Environmentally) in the post Covid19.

\section{6- Declarations}

\section{6-1- Author Contributions}

Conceptualization, P. and L.W.L.; methodology, S.Y.L; software, D.I.S.; validation, P.P., S.Y.L and L.W.L.; formal analysis, S.Y.L.; investigation, D.I.S; resources, S.Y.L; data curation, P.P.; writing-original draft preparation, P.P.; writing - review and editing, S.Y.L; visualization, L.W.L; supervision, L.W.L; project administration, D.I.S.; funding acquisition, S.Y.L All authors have read and agreed to the published version of the manuscript.

\section{6-2- Data Availability Statement}

The data presented in this study are available on request from the corresponding author.

\section{6-3- Funding}

The author received no financial support for the research, authorship, and/or publication of this article. 


\section{6-4- Conflicts of Interest}

The authors declare that there is no conflict of interests regarding the publication of this manuscript. In addition, the ethical issues, including plagiarism, informed consent, misconduct, data fabrication and/or falsification, double publication and/or submission, and redundancies have been completely observed by the authors.

\section{7- References}

[1] Caraka, Rezzy Eko, Yusra Yusra, Toni Toharudin, Rung Ching Chen, Mohammad Basyuni, Vilzati Juned, Prana Ugiana Gio, and Bens Pardamean. "Did Noise Pollution Really Improve during Covid-19? Evidence from Taiwan." Sustainability (Switzerland) 13, no. 11 (2021): 1-12. doi:10.3390/su13115946.

[2] Wen, Jun, Metin Kozak, Shaohua Yang, and Fang Liu. “COVID-19: Potential Effects on Chinese Citizens' Lifestyle and Travel.” Tourism Review 76, no. 1 (2021): 74-87. doi:10.1108/TR-03-2020-0110.

[3] UNWTO. "UNWTO World Tourism Barometer.” World Tourism Organization. Madrid, Spain, (2016).

[4] UNWTO. "Impact assessment of the COVID-19 outbreak on international tourism." (2020).

[5] Jhonson, Shimon, and Peter Boone. From Lockdown to Locked in, Here's What Post-Pandemic Travel Could Look Like. World Economic Forum. World Economic Forum, (2020). Available online: https://www.project-syndicate.org/commentary/covid19long-term-constraints-on-international-travel-by-simon-johnson-and-peter-boone-2020-04 (accessed on May 2021).

[6] Vos, Jonas De. "The Effect of COVID-19 and Subsequent Social Distancing on Travel Behavior." Transportation Research Interdisciplinary Perspectives 5 (2020): 100121. doi:10.1016/j.trip.2020.100121.

[7] The Indonesian COVID-19 Task Force. "Distribution Data of Covid-19 in Indonesia." (2021). Available online: https://covid19.go.id/p/penanganan-covid-19/covid-19-national-task-force-informs-world-community-about-pandemicmitigation (accessed on June 2021).

[8] The Jakarta Post. “COVID-19 Impacts across Indonesia's Business Sectors: A Recap - Business - The Jakarta Post.” The Jakarta Post, 2020. Available online: https://www.thejakartapost.com/news/2020/03/30/Covid-19-impacts-across-indonesias-businesssectors-a-recap.html. (accessed on May 2021).

[9] Wibawa, Tasha. "Bali's Tourism-Dependent Economy Is 'Collapsing' Due to Coronavirus Travel Bans.” ABC News, (2020). Available online: https://www.abc.net.au/news/2020-04-05/bali-tourism-dependent-economy-collapsing-coronavirus/ 12112348. (accessed on May 2021).

[10] Reisinger, Yvette, and Felix Mavondo. "Travel Anxiety and Intentions to Travel Internationally: Implications of Travel Risk Perception.” Journal of Travel Research 43, no. 3 (2005): 212-25. doi:10.1177/0047287504272017.

[11] Nicoll A. Personal (non-pharmaceutical) protective measures for reducing transmission of influenza - ECDC interim recommendations. Euro Surveillance : Bulletin Europeen Sur Les Maladies Transmissibles = European Communicable Disease Bulletin. 2006;11(41): 3061. https://doi.org/10.2807/esw.11.41.03061-en.

[12] Lee, Choong Ki, Hak Jun Song, Lawrence J. Bendle, Myung Ja Kim, and Heesup Han. "The Impact of Non-Pharmaceutical Interventions for 2009 H1N1 Influenza on Travel Intentions: A Model of Goal-Directed Behavior.” Tourism Management 33, no. 1 (2012): 89-99. doi:10.1016/j.tourman.2011.02.006.

[13] Han, Heesup. “Travelers' pro-Environmental Behavior in a Green Lodging Context: Converging Value-Belief-Norm Theory and the Theory of Planned Behavior.” Tourism Management 47 (2015): 164-77. doi:10.1016/j.tourman.2014.09.014.

[14] Wu, Jeanette Mei Lan, Henry Tsai, and Jin Soo Lee. "Unraveling Public Support for Casino Gaming: The Case of a Casino Referendum in Penghu." Journal of Travel and Tourism Marketing 34, no. 3 (2017): $398-415$. doi:10.1080/10548408.2016.1182457.

[15] Ulker-Demirel, Elif, and Gulsel Ciftci. “A Systematic Literature Review of the Theory of Planned Behavior in Tourism, Leisure and Hospitality Management Research.” Journal of Hospitality and Tourism Management 43 (2020): 209-19. doi:10.1016/j.jhtm.2020.04.003.

[16] Ahmad, Wasim, Woo Gon Kim, Zaheer Anwer, and Weiqing Zhuang. "Schwartz Personal Values, Theory of Planned Behavior and Environmental Consciousness: How Tourists' Visiting Intentions towards Eco-Friendly Destinations Are Shaped?” Journal of Business Research 110 (2020): 228-36. doi:10.1016/j.jbusres.2020.01.040.

[17] Eom, Taeyeon, and Heesup Han. "Community-Based Tourism (TourDure) Experience Program: A Theoretical Approach." Journal of Travel and Tourism Marketing 36, no. 8 (2019): 956-68. doi:10.1080/10548408.2019.1665611.

[18] Chinazzi, Matteo, Jessica T. Davis, Marco Ajelli, Corrado Gioannini, Maria Litvinova, Stefano Merler, Ana Pastore y Piontti, et al. "The Effect of Travel Restrictions on the Spread of the 2019 Novel Coronavirus (COVID-19) Outbreak." Science 368, no. 6489 (2020): 395-400. doi:10.1126/science.aba9757. 
[19] Novelli, Marina, Liv Gussing Burgess, Adam Jones, and Brent W. Ritchie. “'No Ebola...still Doomed' - The Ebola-Induced Tourism Crisis.” Annals of Tourism Research 70 (May 2018): 76-87. doi:10.1016/j.annals.2018.03.006.

[20] Maphanga, Petrus Mfanampela, and Unathi Sonwabile Henama. "The Tourism Impact of Ebola in Africa: Lessons on Crisis Management.” African Journal of Hospitality, Tourism and Leisure 8, no. 3 (2019).

[21] Lee, Ming Chi. "Factors Influencing the Adoption of Internet Banking: An Integration of TAM and TPB with Perceived Risk and Perceived Benefit." Electronic Commerce Research and Applications 8, no. 3 (2009): 130-41. doi:10.1016/j.elerap.2008.11.006.

[22] Jarvenpaa, Sirkka L., Noam Tractinsky, Lauri Saarinen, and Michael Vitale. "Consumer Trust in an Internet Store: A CrossCultural Validation.” Journal of Computer-Mediated Communication 5, no. 2 (1999): 45-71. doi:10.1111/j.10836101.1999.tb00337.x.

[23] Aledort, Julia E., Nicole Lurie, Jeffrey Wasserman, and Samuel A. Bozzette. "Non-Pharmaceutical Public Health Interventions for Pandemic Influenza: An Evaluation of the Evidence Base.” BMC Public Health 7 (2007): 208. doi:10.1186/1471-2458-7208.

[24] Deris, Zakuan Zainy, Habsah Hasan, Siti Amrah Sulaiman, Mohd Suhaimi Ab Wahab, Nyi Nyi Naing, and Nor Hayati Othman. "The Prevalence of Acute Respiratory Symptoms and Role of Protective Measures among Malaysian Hajj Pilgrims." Journal of Travel Medicine 17, no. 2 (2010): 82-88. doi:10.1111/j.1708-8305.2009.00384.x.

[25] Sigala, Marianna. "Tourism and COVID-19: Impacts and Implications for Advancing and Resetting Industry and Research." Journal of Business Research 117 (2020): 312-21. doi:10.1016/j.jbusres.2020.06.015.

[26] Raude, Jocelyn, and Michel Setbon. “Lay Perceptions of the Pandemic Influenza Threat.” European Journal of Epidemiology 24, no. 7 (2009): 339-42. doi:10.1007/s10654-009-9351-x.

[27] Oshitani, Hitoshi. "Potential Benefits and Limitations of Various Strategies to Mitigate the Impact of an Influenza Pandemic." Journal of Infection and Chemotherapy 12, no. 4 (2006): 167-71. doi:10.1007/s10156-006-0453-z.

[28] Finkelstein, Stan, Shiva Prakash, Karima Nigmatulina, Tamar Klaiman, and Richard Larson. "Pandemic Influenza: NonPharmaceutical Interventions and Behavioral Changes That May Save Lives.” International Journal of Health Management and Information, 2010.

[29] World Health Organization. SARS: how a global epidemic was stopped. Manila: WHO Regional Office for the Western Pacific, 2006.

[30] Karl, Marion. "Risk and Uncertainty in Travel Decision-Making: Tourist and Destination Perspective." Journal of Travel Research 57, no. 1 (2018): 129-46. doi:10.1177/0047287516678337.

[31] Yang, Chiao Ling, and Vikneswaran Nair. "Risk Perception Study in Tourism: Are We Really Measuring Perceived Risk?" Procedia - Social and Behavioral Sciences 144 (2014): 322-27. doi:10.1016/j.sbspro.2014.07.302.

[32] Wen, Jun, Metin Kozak, Shaohua Yang, and Fang Liu. "COVID-19: Potential Effects on Chinese Citizens' Lifestyle and Travel." Tourism Review 76, no. 1 (2021): 74-87. doi:10.1108/TR-03-2020-0110.

[33] Aro, A. R., A. M. Vartti, M. Schreck, P. Turtiainen, and A. Uutela. "Willingness to Take Travel-Related Health Risks-a Study among Finnish Tourists in Asia during the Avian Influenza Outbreak." International Journal of Behavioral Medicine 16, no. 1 (2009): 68-73. doi:10.1007/s12529-008-9003-7.

[34] Ajzen, Icek, and Martin Fishbein. "Attitude-Behavior Relations: A Theoretical Analysis and Review of Empirical Research." Psychological Bulletin 84, no. 5 (1977): 888-918. doi:10.1037//0033-2909.84.5.888.

[35] Ajzen, Icek. "Nature and Operation of Attitudes." Annual Review of Psychology 52 (2001): 27-58. doi:10.1146/annurev.psych.52.1.27.

[36] Ajzen, Icek, and Arie W. Kruglanski. "Reasoned Action in the Service of Goal Pursuit.” Psychological Review 126 (2019): $774-$ 786. doi:10.1037/rev0000155.

[37] Ajzen, Icek. "The Theory of Planned Behavior." Organizational Behavior and Human Decision Processes 50, no. 2 (December 1991): 179-211. doi:10.1016/0749-5978(91)90020-t.

[38] Perugini, Marco, and Richard P. Bagozzi. "The Role of Desires and Anticipated Emotions in Goal-Directed Behaviours: Broadening and Deepening the Theory of Planned Behaviour.” British Journal of Social Psychology 40, no. 1 (2001): 79-98. doi:10.1348/014466601164704.

[39] Guerin, Rebecca J., and Michael D. Toland. "An Application of a Modified Theory of Planned Behavior Model to Investigate Adolescents' Job Safety Knowledge, Norms, Attitude and Intention to Enact Workplace Safety and Health Skills.” Journal of Safety Research 72 (2020): 189-98. doi:10.1016/j.jsr.2019.12.002. 
[40] Guggenheim, Noga, Orit Taubman - Ben-Ari, and Elisheva Ben-Artzi. "The Contribution of Driving with Friends to Young Drivers' Intention to Take Risks: An Expansion of the Theory of Planned Behavior.” Accident Analysis and Prevention 139 (2020): 105489. doi:10.1016/j.aap.2020.105489.

[41] Song, Hak Jun, Choong Ki Lee, Yvette Reisinger, and Hai Lan Xu. “The Role of Visa Exemption in Chinese Tourists' DecisionMaking: A Model of Goal-Directed Behavior.” Journal of Travel and Tourism Marketing 34, no. 5 (2017): 666-79. doi:10.1080/10548408.2016.1223777.

[42] Kim, Jinkyung Jenny, and Jinsoo Hwang. "Merging the Norm Activation Model and the Theory of Planned Behavior in the Context of Drone Food Delivery Services: Does the Level of Product Knowledge Really Matter?" Journal of Hospitality and Tourism Management 42 (2020): 1-11. doi:10.1016/j.jhtm.2019.11.002.

[43] Han, Heesup, and Sunghyup Sean Hyun. "Drivers of Customer Decision to Visit an Environmentally Responsible Museum: Merging the Theory of Planned Behavior and Norm Activation Theory.” Journal of Travel and Tourism Marketing 34, no. 9 (2017): 1155-68. doi:10.1080/10548408.2017.1304317.

[44] Wu, Jeanette Mei Lan, Henry Tsai, and Jin Soo Lee. "Unraveling Public Support for Casino Gaming: The Case of a Casino Referendum in Penghu." Journal of Travel and Tourism Marketing 34, no. 3 (2017): 398-415. doi:10.1080/10548408.2016.1182457.

[45] Hwang, Jinsoo, Insin Kim, and Muhammad Awais Gulzar. "Understanding the Eco-Friendly Role of Drone Food Delivery Services: Deepening the Theory of Planned Behavior." Sustainability (Switzerland) 12, no. 4 (2020): 1-12. doi:10.3390/su12041440.

[46] Newsom, Jason T., Bentson H. McFarland, Mark S. Kaplan, Nathalie Huguet, and Brigid Zani. "The Health Consciousness Myth: Implications of the near Independence of Major Health Behaviors in the North American Population." Social Science and Medicine 60, no. 2 (2005): 433-37. doi:10.1016/j.socscimed.2004.05.015.

[47] Ophuis, Oude. "Measuring Health Orientation and Health Consciousness as Determinants of Food Choice Behavior: Development and Implementation of Various Attitudinal Scales." In Marketing Thought and Practice in the 1990s, EMAC XVIII, Athens School of Economics and Business, Athens, 1723-25. Athens: EMAC, 1989.

[48] Schifferstein, Hendrik N.J., and Peter A.M. Oude Ophuis. "Health-Related Determinants of Organic Food Consumption in the Netherlands." Food Quality and Preference 9, no. 3 (1998): 119-33. doi:10.1016/S0950-3293(97)00044-X.

[49] Kraft, F. B., and P. W. Goodell. "Identifying the Health Conscious Consumer.” Journal of Health Care Marketing 13, no. 3 (1993): 18-25.

[50] Fagerli, R. Aa, and M. Wandel. “Gender Differences in Opinions and Practices with Regard to a 'Healthy Diet.” Appetite 32, no. 2 (1999): 171-90. doi:10.1006/appe.1998.0188.

[51] Rozin, P., C. Fischler, S. Imada, A. Sarubin, and A. Wrzesniewski. "Attitudes to Food and the Role of Food in Life in the U.S.A., Japan, Flemish Belgium and France: Possible Implications for the Diet-Health Debate." Appetite 33, no. 2 (1999): 163-80. doi:10.1006/appe.1999.0244.

[52] Magnusson, Maria K., Anne Arvola, Ulla Kaisa Koivisto Hursti, Lars Åberg, and Per Olow Sjödén. “Attitudes towards Organic Foods among Swedish Consumers.” British Food Journal 103, no. 3 (2001): 209-27. doi:10.1108/00070700110386755.

[53] Wandel, Margareta, and Annechen Bugge. "Environmental Concern in Consumer Evaluation of Food Quality." Food Quality and Preference 8, no. 1 (1997): 19-26. doi:10.1016/S0950-3293(96)00004-3.

[54] Piko, Bettina F., and Noemi Keresztes. "Physical Activity, Psychosocial Health, and Life Goals among Youth." Journal of Community Health 31, no. 2 (2006): 136-45. doi:10.1007/s10900-005-9004-2.

[55] Jayanti, Rama K., and Alvin C. Burns. "The Antecedents of Preventive Health Care Behavior: An Empirical Study.” Journal of the Academy of Marketing Science 26, no. 1 (1998): 6-15. doi:10.1177/0092070398261002.

[56] Gould, S. J. "Health Consciousness and Health Behavior: The Application of a New Health Consciousness Scale." American Journal of Preventive Medicine 6, no. 4 (1990): 228-37. doi:10.1016/s0749-3797(18)31009-2.

[57] Mai, Robert, and Stefan Hoffmann. "Indirect Ways to Foster Healthier Food Consumption Patterns: Health-Supportive Side Effects of Health-Unrelated Motives.” Food Quality and Preference 57 (2017): 54-68. doi:10.1016/j.foodqual.2016.11.009.

[58] Gineikiene, Justina, Justina Kiudyte, and Mindaugas Degutis. "Functional, Organic or Conventional? Food Choices of Health Conscious and Skeptical Consumers.” Baltic Journal of Management 12, no. 2 (2017): 139-52. doi:10.1108/BJM-01-2016-0016.

[59] Monecke, Armin, and Friedrich Leisch. "SemPLS: Structural Equation Modeling Using Partial Least Squares.” Journal of Statistical Software, 48, (2012). doi:10.18637/jss.v048.i03.

[60] Binsawad, Muhammad Hatim. "Corporate Social Responsibility in Higher Education: A PLS-SEM Neural Network Approach." IEEE Access 8, (2020): 29125-31. doi:10.1109/ACCESS.2020.2972225. 
[61] Caraka, R. E., R. C. Chen, Y. Lee, T. Toharudin, C. Rahmadi, M. Tahmid, and A. S. Achmadi. "Using Multivariate Generalized Linear Latent Variable Models to Measure the Difference in Event Count for Stranded Marine Animals." Global Journal of Environmental Science and Management 7, no. 1 (2021): 117-30. doi:10.22034/gjesm.2021.01.09.

[62] Bartholomew, David, Martin Knott, and Irini Moustaki. "Latent Variable Models and Factor Analysis: A Unified Approach: 3rd Edition.” Latent Variable Models and Factor Analysis: A Unified Approach: 3rd Edition, (2011). doi:10.1002/9781119970583.

[63] Lee, Youngjo, Lars Rönnegård, and Maengseok Noh. "Data Analysis Using Hierarchical Generalized Linear Models with R." Data Analysis Using Hierarchical Generalized Linear Models with R, (2017). doi:10.1201/9781315211060.

[64] Wold, S., H. Martens, and H. Wold. "The Multivariate Calibration Problem in Chemistry Solved by the PLS Method." Matrix Pencils, (1983):286-93. doi:10.1007/bfb0062108.

[65] Han, Heesup, and Yunhi Kim. "An Investigation of Green Hotel Customers' Decision Formation: Developing an Extended Model of the Theory of Planned Behavior." International Journal of Hospitality Management 29, no. 4 (2010): $659-68$. doi:10.1016/j.ijhm.2010.01.001.

[66] Han, Heesup, Li Tzang (Jane) Hsu, and Jin Soo Lee. "Empirical Investigation of the Roles of Attitudes toward Green Behaviors, Overall Image, Gender, and Age in Hotel Customers' Eco-Friendly Decision-Making Process." International Journal of Hospitality Management 28, no. 4 (2009): 519-28. doi:10.1016/j.ijhm.2009.02.004.

[67] Kim, Wansoo, and Chihyung Ok. "The Effects of Relational Benefits on Customers' Perception of Favorable Inequity, Affective Commitment, and Repurchase Intention in Fullservice Restaurants.” Journal of Hospitality and Tourism Research 33, no. 2 (2009): 227-44. doi:10.1177/1096348008329874.

[68] Lee, Choong Ki, Hak Jun Song, Lawrence J. Bendle, Myung Ja Kim, and Heesup Han. "The Impact of Non-Pharmaceutical Interventions for 2009 H1N1 Influenza on Travel Intentions: A Model of Goal-Directed Behavior.” Tourism Management 33, no. 1 (2012): 89-99. doi:10.1016/j.tourman.2011.02.006.

[69] Li, Junxiong, Thi Hong Hai Nguyen, and J. Andres Coca-Stefaniak. "Coronavirus Impacts on Post-Pandemic Planned Travel Behaviours.” Annals of Tourism Research 86 (2021): 102964. doi:10.1016/j.annals.2020.102964.

[70] Wang, Jie, and Brent W. Ritchie. "Understanding Accommodation Managers' Crisis Planning Intention: An Application of the Theory of Planned Behaviour.” Tourism Management 33, no. 5 (2012): 1057-67. doi:10.1016/j.tourman.2011.12.006.

[71] Chen, Mei Fang, and Pei Ju Tung. “Developing an Extended Theory of Planned Behavior Model to Predict Consumers' Intention to Visit Green Hotels.” International Journal of Hospitality Management 36 (2014): 221-30. doi:10.1016/j.ijhm.2013.09.006.

[72] Pahrudin, Pahrudin, Ching Chia-Ying, Liu Li-Wei, and Muhamad Ali. "Intention to Visit of Local Tourist to Destination Image After Disaster: A Structural Equation Model Approach.” Talent Development \& Excellence Vol.12, no. No.3s (2020): 2922 2944.

[73] Zeng, Tian, Fabien Durif, and Elisabeth Robinot. "Can Eco-Design Packaging Reduce Consumer Food Waste? An Experimental Study.” Technological Forecasting and Social Change 162 (2021): 120342. doi:10.1016/j.techfore.2020.120342.

[74] Hair Jr, Joseph F., G. Tomas M. Hult, Christian M. Ringle, and Marko Sarstedt. A primer on partial least squares structural equation modeling (PLS-SEM). Sage publications, (2021):211-213.

[75] Suhr, Diana D. "Exploratory or confirmatory factor analysis?." (2006): 66-76.

[76] Hundleby, John D., and Jum Nunnally. Psychometric Theory. American Educational Research Journal. 3th ed. Vol. 5. New York: McGraw-Hill, (1968). doi:10.2307/1161962.

[77] Fornell, Claes, and David F. Larcker. "Evaluating Structural Equation Models with Unobservable Variables and Measurement Error." Journal of Marketing Research 18, no. 1 (1981): 39. doi:10.2307/3151312.

[78] Caraka, Rezzy Eko, Maengseok Noh, Rung Ching Chen, Youngjo Lee, Prana Ugiana Gio, and Bens Pardamean. "Connecting Climate and Communicable Disease to Penta Helix Using Hierarchical Likelihood Structural Equation Modelling." Symmetry 13, no. 4 (2021): 1-21. doi:10.3390/sym13040657.

[79] Flury, Bernhard, Fionn Murtagh, and Andre Heck. Multivariate Data Analysis. Mathematics of Computation. 3rd ed. Vol. 50. New York: Prentice Hall (Higher Education Division, Pearson Education, (1988). doi:10.2307/2007941.

[80] Fornell, Claes, and David F. Larcker. "Evaluating Structural Equation Models with Unobservable Variables and Measurement Error.” Journal of Marketing Research 18, no. 1 (1981): 39. doi:10.2307/3151312.

[81] Chin, Wynne W. “The Partial Least Squares Approach for Structural Equation Modeling.” Modern Methods for Business Research 295 (1998): 295-336.

[82] Venkatesh, Viswanath, James Y.L. Thong, and Xin Xu. "Consumer Acceptance and Use of Information Technology: Extending the Unified Theory of Acceptance and Use of Technology." MIS Quarterly: Management Information Systems 36, no. 1 (2012): 157-78. doi:10.2307/41410412. 
[83] Flury, Bernhard, Fionn Murtagh, and Andre Heck. Multivariate Data Analysis. Mathematics of Computation. 7th ed. Vol. 50. Harlow: Pearson, (1988). doi:10.2307/2007941.

[84] Armitage, Christopher J., and Mark Conner. "Efficacy of the Theory of Planned Behaviour: A Meta-Analytic Review." British Journal of Social Psychology 40, no. 4 (2001): 471-99. doi:10.1348/014466601164939.

[85] Davis, Larry E., Icek Ajzen, Jeanne Saunders, and Trina Williams. "The Decision of African American Students to Complete High School: An Application of the Theory of Planned Behavior.” Journal of Educational Psychology 94, no. 4 (2002): 810-19. doi:10.1037/0022-0663.94.4.810.

[86] Suhr DD. Exploratory or confirmatory factor analysis? University of Northern Colorado, CO, (2006).

[87] Widiputra, Harya. "GA-Optimized Multivariate CNN-LSTM Model for Predicting Multi-Channel Mobility in the COVID-19 Pandemic.” Emerging Science Journal 5, no. 5 (October 1, 2021): 619-635. doi:10.28991/esj-2021-01300.

[88] Ajzen, Icek. "From Intentions to Actions: A Theory of Planned Behavior.” Action Control, (1985): 11-39. doi:10.1007/978-3642-69746-3_2.

[89] Quintal, Vanessa Ann, Julie Anne Lee, and Geoffrey N. Soutar. "Risk, Uncertainty and the Theory of Planned Behavior: A Tourism Example.” Tourism Management 31, no. 6 (2010): 797-805. doi:10.1016/j.tourman.2009.08.006.

[90] Sönmez, Sevil F., and Alan R. Graefe. "Influence of Terrorism Risk on Foreign Tourism Decisions." Annals of Tourism Research 25, no. 1 (1998): 112-44. doi:10.1016/s0160-7383(97)00072-8.

[91] Lim, Nena. "Consumers' Perceived Risk: Sources versus Consequences." Electronic Commerce Research and Applications 2, no. 3 (2003): 216-28. doi:10.1016/S1567-4223(03)00025-5.

[92] Al-Ansi, Amr, Hossein G.T. Olya, and Heesup Han. "Effect of General Risk on Trust, Satisfaction, and Recommendation Intention for Halal Food.” International Journal of Hospitality Management 83 (2019): 210-19. doi:10.1016/j.ijhm.2018.10.017.

[93] Olya, Hossein G.T., and Amr Al-ansi. "Risk Assessment of Halal Products and Services: Implication for Tourism Industry." Tourism Management 65 (2018): 279-91. doi:10.1016/j.tourman.2017.10.015.

[94] Bauer, R. “Comsumer Behavior as Risk Taking.” Risk Taking and Information Handling in Consumer Behavior. Chicago, IL, (1967).

[95] Lee, Chung Chieh, and Chih Jen Chen. "The Reaction of Elderly Asian Tourists to Avian Influenza and SARS." Tourism Management 32, no. 6 (2011): 1421-22. doi:10.1016/j.tourman.2010.12.009. 